\title{
Agitated thin-film drying of spinach juice
}

\section{Qiu, J.*; Boom, R. M.; Schutyser, M.A.I.}

Laboratory of Food Process Engineering, Wageningen University, Wageningen, The Netherlands

*E-mail of the corresponding author: jun.qiu@wur.nl

\begin{abstract}
Agitated thin film dryers (ATFD) has been considered as an effective technology for drying viscous liquid foods, pastes or pureed foods. In this study, a lab-scale ATFD was developed and applied for drying of juices from spinach leaves at varying temperature $\left(60-90{ }^{\circ} \mathrm{C}\right)$, feed rate $(0.3-0.5 \mathrm{~kg} / \mathrm{h})$ and blade rotation speed (300 - 600 RPM) combinations. Juice suspensions were successfully dried into powder with a moisture content ranging from 0.049 to $0.114 \mathrm{~kg} / \mathrm{kg}$ total. Increasing the wall temperature and feed rate were found to improve the specific evaporation rate and evaporation rate of the ATFD, respectively. The blade rotation speed had limited effect on the water removal rate, while it played a crucial role in powder formation.
\end{abstract}

Keywords: Food solution; Spinach juice; Thin film drying; Scraped surface; Vacuum conductive drying. 


\section{Introduction}

Drying is a commonly used technology to preserve food products. Various types of dryers have been developed that are tailored to specific feed properties and product requirements [1]. The most commonly applied drying technologies to liquid feeds can be categorized into two types, i.e. convective and conductive drying. Spray drying is one of the most commonly applied convective drying methods, where energy for evaporation is supplied by hot air to the product that is dispersed in micron-sized droplets [2]. Drum and agitated thin film drying are conductive drying methods, where energy for evaporation is supplied by steam condensation and transferred via a wall to the product that is applied at the other side. Whereas drum drying is more readily applied and effective for drying of viscous liquid foods, pastes or pureed foods, agitated thin film drying is not yet widely applied [1, 3]. Comparing to spray drying, drum drying is more efficient as it consumes on average $40 \%$ less energy due to a.o. lower energy loss via the exhaust gas [2, 4]. A major drawback of atmospheric drum drying is however that the product is exposed to the boiling temperature $\left(100^{\circ} \mathrm{C}\right)$, which can lead to undesired damage to heat sensitive foods [1, 3]. Operation of drum drying processes under reduced pressure could be an attractive alternative as well, but capital costs of vacuum drum dryers are relatively large. Agitated thin film drying (ATFD) is therefore identified as a promising alternative conductive drying method.

Only very few studies investigated ATFD. Pawar et $1 .[1,5]$ mathematically studied the heat transfer and mass transfer during ATFD and proposed a stage-wised penetration theory model, by assuming ideal mixing between the bow wave and the thin film. However, the model was validated with ATFE instead of ATFD experiments. Because during ATFD the feed will transform from a viscous liquid into a paste and subsequently into a powder, this may be expected to have large influence on the mass and heat transfer during operation [6]. Hitherto, to the best of our knowledge no experimental studies have systematically investigated product transformation during ATFD drying and its consequence on the drying

behaviour. It may be expected that the product properties will have large influence on the drying behaviour in an ATFD.

The aim of this study was therefore to obtain better understanding of drying behaviour of foods during ATFD drying and how this is influenced by process. Suspensions prepared from spinach leaves were selected as model system to investigate the influence of drying parameters, i.e. heating temperatures, feeding rates and rotation speeds.

\section{Materials and Methods}

\subsection{Material}

Spinach suspensions for ATFD experiments were prepared starting from fresh spinach leaves, which were purchased from the local supermarket. The fresh spinach leaves were 
juiced by an Angelia AG-7500 Juicer (Angel Co. Ltd, Republic of Korea). After juicing, the squeezed juice and fibre residues were collected separately. The obtained insoluble fibre residues were dried by a hot air oven (Binder, Tuttlingen, Germany) at $60{ }^{\circ} \mathrm{C}$ for 20 hours. The dried fibres were milled by the Rotor Mill Pulverisette-14 (FRITSH International, USA) at 6000 RPM with a $0.2 \mathrm{~mm}$ sieve. The drying and milling of fibres was necessary because the fibre particles had to be small enough to avoid blockage of the feeding pump. Subsequently, the milled fibres were added back into the squeezed juice to obtain a spinach suspension with approximately again $2 \%$ w/w fibers. In addition, around 5 drops of Antifoam B aqueous silicone emulsion (Sigma-Aldrich ${ }^{\circledR}$, Zwijndrecht, Netherlands) was added into 1 litre juice to prevent excessive foaming.

\subsection{Lab-scale Agitated Thin Film Drying}

A lab-scale agitated thin film dryer was custom build for the experiments. The ATFD chamber was made from transparent glass to facilitate observation of the used heat exchange area. The ATFD chamber was equipped with a Liebig condenser and a dropping funnel (L.G.S. B.V, Ubbena, Netherlands) to condense and quantify the vapour release. The entire system was operated under reduced pressure (50 mbar) using a vacuum pump (type, country). Experiments were performed to determine the (specific) evaporation rates of the spinach suspensions at different drying conditions. The spinach suspension was preheated to $33{ }^{\circ} \mathrm{C}$ and then supplied to the system with a flow rate ranging from $0.3 \mathrm{~kg} / \mathrm{h}$ to $0.5 \mathrm{~kg} / \mathrm{h}$. The drying temperatures of the heating chamber ranged from 70 to $90{ }^{\circ} \mathrm{C}$. The condenser was operated with cooling water of $2{ }^{\circ} \mathrm{C}$. The amount of condensed water was measured and used to obtain the evaporation rate. The specific evaporation rate was calculated by dividing by the evaporation rate by the used heat exchange area.

\subsection{Analysis of the moisture content and water activity}

Powders were collected at the bottom of the lab-scale ATFD for analysis of the moisture content and water activity. To determine the moisture content, around $1.5 \mathrm{~g}$ of the powder was dried in a hot air oven (Binder, Tuttlingen, Germany) at $105{ }^{\circ} \mathrm{C}$ for 16 hours. The water activity was measured by an AquaLab 4TE dew point water activity meter (METER Food, Munich, Germany). Measurements were carried out in duplicate.

\section{Results and discussion}

The lab-scale ATFD setup was used to dry the prepared spinach suspensions at different drying conditions, which are reported in Table 1 . The effect of the drying temperature on the evaporation rate and the specific evaporation rate was determined, as shown Fig. 1. Fig. 
1 (A, B) showed that with the increase of drying temperature, the evaporation rate did not change significantly ( $p>0.05$ ), while the specific evaporation rate significantly increased ( $\mathrm{p}<0.05$ ), based on one-way ANOVA analysis. This is because at higher drying temperature, the surface area used for drying decreased, as shown in Fig. 1 (C). The smaller surface area used for drying in this situation is related to the higher heat flux from the hot wall towards the sample at increased wall temperatures, which results in a higher specific evaporation rate. In this case the maximum feed rate can be increased, which benefits the capacity of the equipment.

$\mathbf{A}$

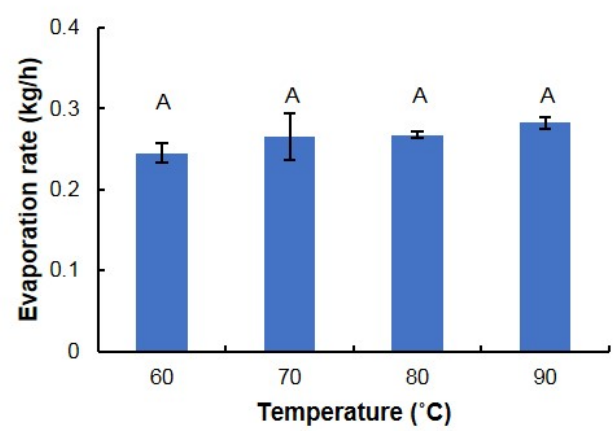

C

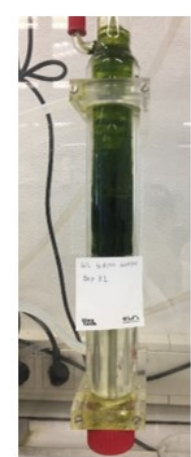

$60{ }^{\circ} \mathrm{C}$

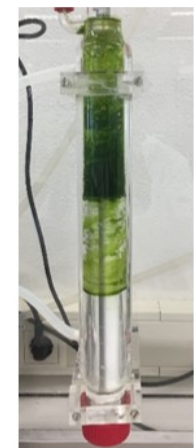

$70{ }^{\circ} \mathrm{C}$

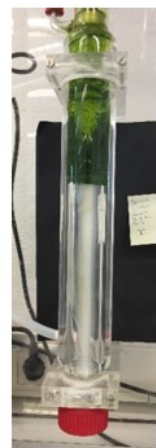

$80^{\circ} \mathrm{C}$

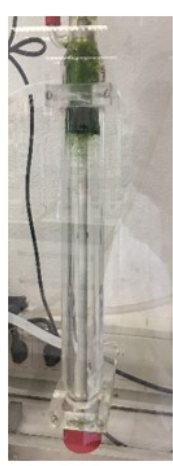

$90{ }^{\circ} \mathrm{C}$

Fig. 1(A) The evaporation rate and (B) the specific evaporation rate in the ATFD for different temperatures (Rotation speed $=600 \mathrm{RPM}$, Feed rate $=0.3 \mathrm{~kg} / \mathrm{h}$ ). The error bars represent the standard deviation of the experimental data $(n=3)$. The same letters represent no significant difference at the $95 \%$ confidence interval. (C) The visual image of usage the ATFD chamber under different drying temperatures. 
Table 1 The fraction of the used heating exchange area, the moisture content and water activity of the powder at different drying conditions

\begin{tabular}{|c|c|c|c|c|c|c|c|}
\hline \multirow[b]{2}{*}{ No. } & \multicolumn{4}{|c|}{ Drying conditions } & \multirow{2}{*}{$\begin{array}{l}\text { Fraction } \\
\text { of used } \\
\text { heating } \\
\text { area }(-)^{*}\end{array}$} & \multirow{2}{*}{$\begin{array}{c}\text { Moisture } \\
\text { content } \\
\text { (kg/kg } \\
\text { total)* }\end{array}$} & \multirow[b]{2}{*}{$\begin{array}{l}\text { Water } \\
\text { activity } \\
\left(\mathrm{a}_{\mathrm{w}}\right)^{*}\end{array}$} \\
\hline & $\begin{array}{c}\text { Feed } \\
\text { rates } \\
(\mathrm{kg} / \mathrm{h})\end{array}$ & $\begin{array}{c}\text { Drying } \\
\text { temperature } \\
\left({ }^{\circ} \mathrm{C}\right)\end{array}$ & $\begin{array}{c}\text { Rotation } \\
\text { speed } \\
\text { (RPM) }\end{array}$ & $\begin{array}{l}\text { Vacuum } \\
\text { (mbar) }\end{array}$ & & & \\
\hline 1 & 0.3 & 60 & 600 & 50 & $\begin{array}{c}0.58^{\mathrm{a}} \pm \\
0.03\end{array}$ & $\begin{array}{c}0.096 \pm \\
0.009\end{array}$ & $\begin{array}{c}0.55 \pm \\
0.02\end{array}$ \\
\hline 2 & 0.3 & 70 & 300 & 50 & $\begin{array}{c}0.38^{\mathrm{b}} \pm \\
0.05\end{array}$ & $\mathrm{NaN}^{* *}$ & $\mathrm{NaN}^{* *}$ \\
\hline 3 & 0.3 & 70 & 400 & 50 & $\begin{array}{c}0.42^{\mathrm{ab}} \pm \\
0.11\end{array}$ & $\begin{array}{c}0.087 \pm \\
0.002\end{array}$ & $\begin{array}{c}0.57 \pm \\
0.02\end{array}$ \\
\hline 4 & 0.3 & 70 & 500 & 50 & $\begin{array}{c}0.39^{\mathrm{b}} \pm \\
0.04\end{array}$ & $\begin{array}{c}0.102 \pm \\
0.001\end{array}$ & $\begin{array}{c}0.58 \pm \\
0.01\end{array}$ \\
\hline 5 & 0.3 & 70 & 600 & 50 & $\begin{array}{c}0.38^{\mathrm{b}} \pm \\
0.07\end{array}$ & $\begin{array}{c}0.114 \pm \\
0.003\end{array}$ & $\begin{array}{c}0.60 \pm \\
0.01\end{array}$ \\
\hline 6 & 0.3 & 80 & 600 & 50 & $\begin{array}{c}0.29^{\mathrm{bc}} \pm \\
0.01\end{array}$ & $\begin{array}{c}0.078 \pm \\
0.013\end{array}$ & $\begin{array}{c}0.53 \pm \\
0.03\end{array}$ \\
\hline 7 & 0.3 & 90 & 600 & 50 & $\begin{array}{c}0.20^{\mathrm{cd}} \pm \\
0.02\end{array}$ & $\begin{array}{c}0.049 \pm \\
0.002\end{array}$ & $\begin{array}{c}0.26 \pm \\
0.07\end{array}$ \\
\hline 8 & 0.4 & 90 & 600 & 50 & $\begin{array}{c}0.29^{\mathrm{bd}} \pm \\
0.02\end{array}$ & $\begin{array}{c}0.071 \pm \\
0.031\end{array}$ & $\begin{array}{c}0.46 \pm \\
0.19\end{array}$ \\
\hline 9 & 0.5 & 90 & 600 & 50 & $\begin{array}{c}0.34^{\text {bd }} \pm \\
0.08\end{array}$ & $\begin{array}{c}0.098 \pm \\
0.071\end{array}$ & $\begin{array}{c}0.56 \pm \\
0.20\end{array}$ \\
\hline
\end{tabular}

a-d : The same letters represent no significant difference at the 95\% confidence level;

* : Each value is expressed as mean $\pm \mathrm{SD}$;

**: Not a number.

Fig. 2 and Fig. 3 shows the influence of the rotation speed and the feed rate on the evaporation rate and the specific evaporation rate. From Fig. 2, we can observe that both the evaporation rate and the specific evaporation rate did not change at different rotation speeds ( $p>0.05$ ). This observation is opposite to simulations with the model proposed by Pawar et al. [1]. Pawar et al. [1] proposed that the heat transfer coefficient of the ATFD may be derived from the heat penetration theory and increases with the rotation speed. Therefore, the specific evaporation rate should increase as well. However, Pawar et al. [1] also experimentally observed that the water evaporation rate was independent of the speed of the blades, when they concentrated the $20 \% \mathrm{w} / \mathrm{w}$ ammonium sulphate solution in an ATFE. The differences between the experimental data and the model predictions are discussed later in more detail. 
According to Fig. 3, we found that the effect of the feed rate is opposite to that of the temperature. The increased feed rate resulted in an increase in the evaporation rate $(\mathrm{p}<$ 0.05 ) while it did not affect the specific evaporation rate $(\mathrm{p}>0.05)$, which can be explained by the increased usage of heat exchange area (Table 1).

Table 1 shows the moisture content and water activity $\left(\mathrm{a}_{\mathrm{w}}\right)$ of the dried spinach powder and the fraction of dissolved powder at different drying conditions. It can be seen that the moisture content of the powder ranges from 0.049 to $0.114 \mathrm{~kg} / \mathrm{kg}$ total and the water activity of the powder ranges from 0.26 to 0.60 . Although foods with $a_{w}<0.6$ may be considered as microbiologically stable, further drying in for example a fluidized bed would be recommended for vegetable powders to further decrease the water activity to aw $<0.2$ [7]. It should be mentioned that during experiment No. 2, no powder was produced. Probably this was due to the low rotation speed, which did not provide enough shear stress to fracture the material. Therefore, even though the rotation speed does not affect the heat transfer (Fig. 2), it plays a crucial role to induce powder formation.

A

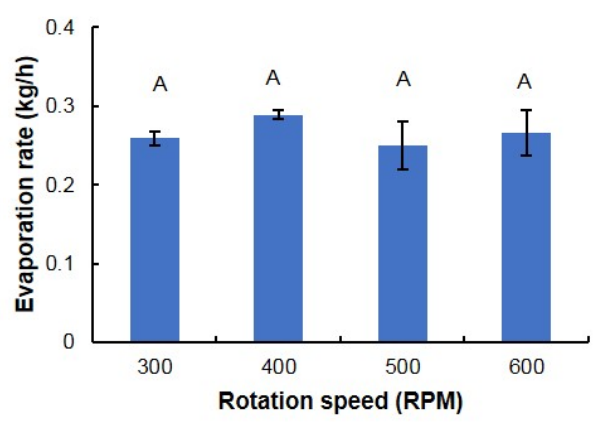

B

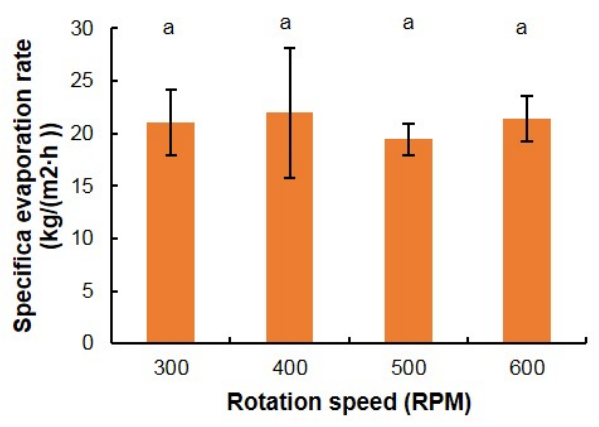

Fig. 2 (A) The evaporation rate and (B) the specific evaporation rate in the ATFD for different rotation speeds (Temperature $=70{ }^{\circ} \mathrm{C}$, Feed rate $=0.3 \mathrm{~kg} / \mathrm{h}$ ). The error bars represent the standard deviation of the experimental data $(n=3)$. The same letters represent no significant difference at the $95 \%$ confidence interval. 
A

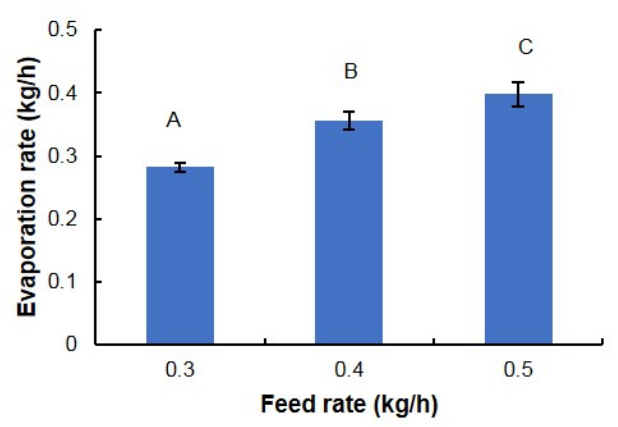

B

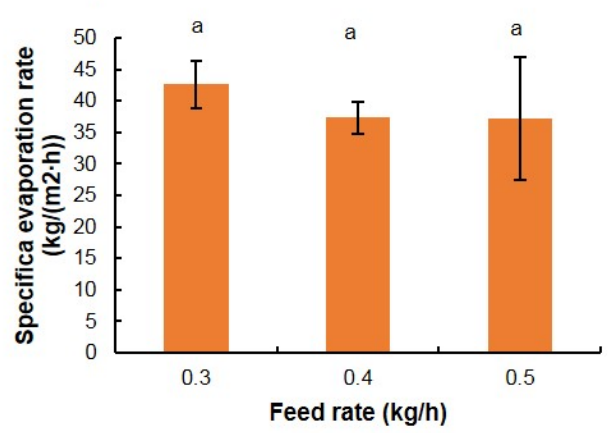

Fig. 3 (A) The evaporation rate and (B) the specific evaporation rate in the ATFD for different feed rates (Temperature $=90{ }^{\circ} \mathrm{C}$, Rotation speed $\left.=600 \mathrm{RPM}\right)$. The error bars represent the standard deviation of the experimental data $(n=3)$. The same letters represent no significant difference at the $95 \%$ confidence interval.

\section{Conlusion}

In this study suspensions prepared from spinach leaves were dried in a lab-scale agitated film dryer under different conditions. Obtained spinach powders were flowable, although the final moisture contents were relatively high. The drying behaviour was characterised and especially wall temperature appeared to determine the specific evaporation rate, which can benefit the dryer capacity. Surprisingly, blade rotation speed did not affect the drying rate, but appeared crucial to break up the material into small powder particles during the process.

\section{References}

[1] Pawar, S.B., et al., Mathematical modeling of agitated thin-film dryer. Drying Technology, 2011. 29(6): p. 719-728.

[2] Devahastin, S. and A.S. Mujumdar, Indirect dryers, in Handbook of Industrial Drying, Fourth Edition. 2006, CRC Press: Boca Raton. p. 137-149.

[3] Daud, W.R.W., Drum Dryers, in Handbook of Industrial Drying, Fourth Edition. 2006, CRC Press: Boca Raton.

[4] Nindo, C. and J. Tang, Refractance window dehydration technology: a novel contact drying method. Drying Technology, 2007. 25(1): p. 37-48.

[5] Pawar, S.B., A. Mujumdar, and B. Thorat, Flow pattern and heat transfer in agitated thin film dryer. Chemical Engineering and Processing: Process Intensification, 2011. 50(7): p. 687-693. 
[6] Zeboudj, S., et al., Modelling of flow in a wiped film evaporator. Chemical Engineering Science, 2006. 61(4): p. 1293-1299.

[7] Quek, S.Y., N.K. Chok, and P. Swedlund, The physicochemical properties of spraydried watermelon powders. Chemical Engineering and Processing: Process Intensification, 2007. 46(5): p. 386-392. 